\title{
CARTAS SOBRE A DANÇA DE NOVERRE: DESORDEM, TRANSGRESSÕES E OUTROS DESCAMINHOS PARA CRIAÇÃO
}

\author{
Airton Ricardo Tomazzoni dos Santos \\ Doutor em Educação/UFRGS \\ Diretor do Centro Municipal de Dança da Prefeitura Municipal de Porto Alegre \\ airtontomazzoni@gmail.com
}

O objetivo desse artigo é mobilizar conceitos e perspectivas teóricas alinhavadas na obra Cartas sobre a Dança, de Jean-Georges Noverre, produzida no século XVIII, mas que apresenta elementos para problematização das poéticas das artes cênicas na contemporaneidade. Sua visão peculiar de compreender a dança como imitação da natureza e as implicações de percepção das dinâmicas implícitas nessa natureza permitem a emergência e valorização de aspectos usualmente relegados naquele período, como desordem, instabilidade, multiplicidade, singularidade, indeterminação como configuradoras também do processo de criação. A tensão entre técnica e expressividade, a questão entre cópia e inventividade, a relação entre racionalidade e emoção no processo artístico, a proximidade entre arte e vida, a atenção ao acaso e à irregularidade, ou ainda o caráter perigoso e subversivo da inventividade. Enfim, um movimento de perceber o alcance das proposições e a importância de revisitar esse material teórico/filosófico/pedagógico/artístico ainda pouco valorizado nas discussões atuais.
The purpose of this article is to mobilize concepts and theoretical perspectives outlined on Jean-Georges Noverre's Letters on Dancing, produced in the eighteenth century, in which includes elements for questioning the poetics of performing arts in contemporary times. His peculiar vision to understand dance as imitation of nature and the implications of the perception over implied dynamics in this nature allow the emergence and recovery of aspects usually relegated in that period, such as disorder, instability, multiplicity, uniqueness, indeterminacy, all of them also as structures for the creation process. The tension between technique and expressiveness, the question about copying and inventiveness, the relationship between rationality and emotion in the artistic process, the proximity between art and life, attention to chance and irregularity, or the dangerous and subversive character of inventiveness. Finally, a movement to realize the scope of the proposals and the importance of revisiting this theoretical / philosophical / educational / artistic material still little valued in current discussions.

Dance. Creation. Aesthetics 
Alguns movimentos sempre me pareceram nocivos ao saber: achar que nada deve haver de importante num material sem nunca se debruçar sobre ele, o ato de se acreditar que a literatura mais atualizada é que a realmente interessa e a crença de não se autorizar produções teóricas alinhavadas fora de um contexto específico passíveis de diálogo frutífero com outros contextos artísticos/teóricos. Essa percepção recorrente revela-se de muitas maneiras na atuação docente/artística, com muitos exemplos que poderiam ser resgatados. Mas nesse artigo busco, dentro de limite de um exercício conciso, trafegar por um material dessa linhagem: as Cartas sobre a dança ${ }^{1}$, de Jean Georges Noverre (1727-1810). E sim, o propósito de insistir em retomadas constantes e mais frequentes desse material ainda à margem como subsídio teórico fértil, amplo, inquietante e decisivo para se pensar questões estéticas/pedagógicas/políticas que a dança continua suscitando para artes da cena contemporânea e não apenas para própria dança, campo no qual usualmente é aprisionado Noverre.

Esse mestre de balé do século XVIII talvez possa representar por si um provocativo ponto de sinalização do empobrecimento e da cilada pelas quais nos deixamos muitas vezes levar quando se assume a perspectiva histórica de alojar artistas/pensadores em períodos cronológicos dos quais podem dar conta. ${ }^{2} \mathrm{Em}$ suas

1 Letters sur la Danse teve sua primeira versão editada em 1760 em Stuttgart e Lyon, num total de quinze cartas. Essa edição foi intitulada Letters sur la Danse et sur les ballets. Depois tiveram as versões de Londres, em 1783; São Petsburgo (1804), Paris (1807), além de novas edições no século XX.

2 Aqui reconheço o alerta que André Levinson, responsável pelo prefácio das Cartas na edição de 1927. "Levinson alerta para as dificuldades de interpretação das ideias do reformador, sobretudo se ignorarmos o fato de ele ter sido um criador plenamente integrado à sua época"(Monteiro, 1998, p.15). Mas me permitirei o exercício de leitura que buscas vestí-
Cartas, arrisco afirmar, Noverre revela aspectos que serão valiosos à modernidade, apresentada na dança, com esse rótulo apenas um século mais tarde, bem como às problemáticas e análises que cercam a dança e as artes da cena, ainda nos tempos atuais. A tensão entre técnica e expressividade, a questão entre cópia e inventividade, a relação entre racionalidade e emoção no processo artístico, a proximidade entre arte e vida, a atenção ao acaso e à irregularidade, ou ainda o caráter perigoso e subversivo da inventividade. Ainda que postuladas muitas vezes sem utilizar esses termos ou conceitos, pode-se perceber a habilidade em identificá-los, em descrevê-los e em problematizá-los sem fugir de suas complexidades.

Por isso, pretendo pontuar alguns dos muitos aspectos de grande relevância e pertinência que suas Cartas oferecem às discussões relativas à criação em dança que ainda atravessam discussões, pesquisas e fazeres na contemporaneidade.

\section{Razão, emoção e imaginação}

$\mathrm{Na}$ Carta 4 talvez se tenha um dos trechos que conseguem sintetizar de maneira contumaz uma série de princípios que envolvem a criação em dança. Nesse trecho o autor destaca que "O êxito nas composições somente é possível se o coração se inquieta, se a alma com vivacidade se emociona, se a imaginação se incendeia, se as paixões trovejam e o gênio clareia" (Monteiro, 1998, p. 213). O mestre

gios, ou melhor, chaves de também entender seus conceitos que talvez possam fazer sentido ao serem cotejados com questões contemporâneas da poética da dança. Uma liberdade interpretativa responsável e provocativa, fiel às suas próprias Cartas de Noverre. 
oitocentista estava já a alertar para que uma composição de dança deveria articular aspectos muitas vezes ignorados ou negligenciados por criadores e mestres de dança daquele período. Muitas vezes foi dada à razão, em outros à emoção a tônica da criação em dança. Por um lado, a crença na valorização superior de uma elaboração mental, encarando emoção e sentimento como ameaçadores a esse processo, por outro, o arroubo sentimental traduzido em movimento, em risco de ser maculado por conceitos e racionalismos perniciosos.

Historicamente essa dicotomia aparece de inúmeras maneiras. Aparece na rivalidade de duas consagradas bailarinas Marie Camargo (1710-1770) - considerada de grande habilidade técnica - e Marie Sallé (1707-1756) - que brilhava pela dramaticidade e expressividade, como se deteve Roberto Pereira (2000). Aparece na separação simplista de oposição entre uma dita dança conceitual contemporânea e as catárticas e arrebatadoras performances das divas midiáticas do videoclipe.

Não estaria Noverre tentando propor uma nova racionalidade de criação que escapasse dessa polaridade? Uma racionalidade que não deve excluir nem a engenhosidade, nem a emocionalidade. Em síntese, Noverre parece se recusar a pensar o corpo que dança, separando razão de emoção, pensamento de sentimento. Como diria, quase dois séculos depois, o neurocientista Antonio Damásio (1998), em sua obra O erro de Descartes: "penso e sinto, logo existo".

$\mathrm{E}$, ao "fazer as pazes" entre razão e emoção, ele complexifica ainda mais a questão estética ao incluir nela a imaginação com igual importância nesse processo. Ou seja, não é a articulação de um binarismo que liga um ponto no outro, mas de uma trama que se tece e que não tem hierarquia de um aspecto sobre o outro. Além da metáfora poderosa, suas colocações buscam coordenar coração inquietos, com paixões ruidosas e ainda com um pensamento curioso, inventivo, vívido e emocionado. Não é apenas um complexo e ambíguo jogo de palavras, mas uma senha para escapar dos determinismos redutores de compreender técnica e performance por vias excludentes ou unívocas.

Singularidade e diferença como condição de criação

Outro dos pilares do balé de ação, preconizado por Noverre, é o de considerar a arte da dança como imitação da natureza. E aqui, não é a imitação representativa do que está na natureza como rios, nuvens, fogo, animais e tipos humanos. Há, na sua primeira carta, a afirmação da natureza em que a vida humana se afirma. E é essa natureza, que se faz de todas as gradações possíveis, que o autor chama de paixões, que incluem comportamentos emocionais, mas também sensações, pensamentos, sonhos, ideais. Uma natureza humana é também feita da sua capacidade de não se reduzir a seus instintos de sobrevivência. Com isso, ele reafirma novamente a razão, a emoção e a imaginação como balizadores dessa natureza humana.

Como aparece na Carta 1:

As paixões, sendo as mesmas em todos os homens, diferem na proporção de suas sensações; elas se imprimem e se exercem com mais ou menos força sobre uns que sobre outros e manifestam-se exteriormente com mais ou menos veemência e impetuosidade (Monteiro, 1998, p.189). 
Sendo todos humanos, somos indivíduos com singularidade e diferença de ações. O seu balé de ação, portanto, é uma dança que se anuncia atenta à infinidade de gradações possíveis que a existência possibilita, sujeita a indeterminações e acasos que definem a diversidade de modos e alternativas possíveis, reais ou imaginadas.

Ele prossegue na Carta 6 reafirmando a pluralidade ao dizer que:

[...] um mestre de balé precisa conhecer as belezas e as imperfeições da natureza, pois esse estudo permitirá fazer uma escolha acertada de cenas que serão ora poéticas, ora históricas, ora críticas, ora alegóricas e morais. Não poderá deixar de inspirar-se em modelos tirados de todas as posições sociais, de dos os estados, de todas as condições" (ibdem, p.227).

Mesmo que em determinados trechos ele fale em buscar a virtude, proporção, harmonia e beleza, Noverre assinala que cabe "embelezar a natureza sem desfigurá-la", demonstrando uma tensão entre os cânones da época e os caminhos que ele começa a esboçar, talvez sem o devido vocabulário para traduzir ambiguidades e complexidades envolvidas.

Essa configuração estética que Noverre vai desenhando indica alguns desdobramentos inerentes a essas asserções: a valorização dos intérpretes na sua individualidade ao invés de sua padronização, a necessidade de se abrir às variáveis possíveis e não a modelos (técnica) e recursos limitadores (como perucas e máscaras, como regra obrigatória daquela época) e a habilidade de se resistir a padrões insuficientes para dar conta dessa dança que flerta com a existência humana. Uma existência feita de modos que não cabem necessariamente em simetrias, ordenação, previsibilidade restri- tiva. Novamente ecos de contemporaneidade antecipada ou sinalização de que a contemporaneidade não está restrita ao nosso tempo apenas?

As Cartas permitem notar a sintonia possível com considerações sobre a poética contemporânea de dança. "Por outras palavras, tratase não tanto do que trabalha a dança, mas do que a própria dança trabalha, o meio humano no qual ela desenvolve as suas possibilidades e de que ela própria propõe um saber (e uma interpretação)" (Louppe, 2012, p.35). Noverre esteve atento a esse meio humano no qual a dança é produzida e sua coerência de ação, buscando a natureza intrínseca a essa condição e não alheia a ela. A imitação da natureza proposta por Noverre, incluía aceitar a lógica do "meio humano" no qual da dança é produzida, a lógica na qual cada situação precisa ser "resolvida" por ela mesma.

Desordem, desvios, transgressões e outros descaminhos para criação

Seguindo por esses aspectos defendidos, Noverre tenta combater boa parte do formalismo e rigidez de modelos impostos à criação do balé ao longo do século XVIII. Na Carta 10 ele vaticina:

Se o port de bras deve ser tão variado quanto as diferentes paixões que a dança é capaz de exprimir, as regras aprendidas acabam por tornar-se praticamente inúteis. Será preciso transgredi-las e delas se afastar constantemente, opondo-se sempre que deixarem de seguir exatamente os movimentos da alma, que não se limitam necessariamente a um número limitados de gestos (Monteiro, 1998, p.298). 
Ele não recusa as regras, nem a técnica aprendida, mas relativiza seus usos e finalidades. Como ele sublinha, as posições de braços que o balé estabeleceu como base de sua metodologia de ensino não devem se esgotar nelas mesmas. O vocabulário coreográfico deve ser o princípio e não o fim, devendo servir de horizonte e não de limite. Aqui são perceptíveis os ecos de um fazer artístico desviante dos circuitos oficiais e reconhecidos no século XVIII. Talvez o mestre de balé francês estivesse quase postulando um "fazer" que, enquanto faz, inventa o "modo de fazê-lo", não totalmente estranha à perspectiva estética defendida por filósofos do século XX como o italiano Luigi Pareyson (1993; 1997). Noverre anuncia um outro entendimento para o conceito de técnica e uma outra relação no processo de criação.

$E$ ele não se opõe apenas à técnica na formação, mas à estruturação rígida de criação. Na Carta 13 ataca: "Sim, Senhor, a coreografia amortece o engenho, apaga e enfraquece o gosto do compositor que a utiliza, torna-se pesado, sem graça, incapaz de invenção" (Monteiro, 1998, p. 350). E aqui a coreografia que ele critica é aquela estruturada sempre a partir das mesmas danças, das mesmas sequências, dos mesmos passos, sem espaço para que nada se modifique ou permita questionar sua ordenação.

E como enfatiza na sua primeira Carta, ele questiona a ordem, não pelo gesto anárquico que pode representar esta oposição, mas por compreender que dentro da variedade de organizações possíveis da existência humana, da vida, da natureza, muitas formas podem ser estabelecidas ou postuladas. "Não prego a desordem e a confusão; quero, ao contrário encontrar regularidade em meio a própria irregularidade" (ibdem, p. 189). Desse modo apa- rece um grau de liberdade que procura outra lógica de organização para o ato coreográfico que pudesse se permitir construir ordens coerentes em si e não a priori. Isso soa familiar quando a dança pós-moderna americana, na década de 1960, rebela-se contra a ordem, mas sem proclamar o caos. "Se a improvisação levava em conta a liberdade de escolha e de ação, não obstante era qualquer coisa, menos anárquica" (Banes, 1999, p. 279). O mestre de balé via nos descaminhos usuais da instabilidade, indeterminação e desordem da vida, uma nova lógica capaz de indicar caminhos profícuos para arte da cena.

Ainda na primeira Carta pode-se verificar essa compreensão em proposições como "uma cena deve oferecer uma desordem bela", cogitando que a beleza também se estabelece na suposta desorganização. Também ao criticar a polaridade de uma cena entre dois extremos apenas, ele alerta para "quantas gradações e degradações a ser observadas para que desses dois sentimentos resulte uma multiplicidade de quadros". E quando a diversidade precisa ser encontrada, a simetria "deve ser banida", insiste Noverre. E questiona os "submissos aos hábitos e cheios de preconceitos, se encontram simetria em um bando de ovelhas que procura escapar dos dentes mortíferos dos lobos". Enfim, a dinâmica da vida, assumida como se estabelece seja com degradações, desordens belas, diversidades e multiplicidades que escapam à formulas empobrecedoras.

\section{Atenção ao momento}

A Carta 13 também acrescenta outro destaque que aparece com relevo: 
A conduta e a marcha de um grande balé, bem desenhado, exige Senhor, conhecimento, espírito, engenho, finura, um tato certeiro, uma sábia cautela e um golpe de vista infalível, e todas essas qualidades não se adquirem decifrando ou escrevendo a dança coreograficamente. É o momento que determina a composição, e a habilidade consiste em captá-lo a contento (Monteiro, 1998, p. 349).

Captar o momento, o instante presente que não se coloca antecipadamente, mas apenas como acontecimento, emergência. Noverre aponta para a importância dos eventos que se colocam em sua imprevisibilidade, instáveis, fugidios. Suas coreografias provavelmente ainda operavam longe da noção de improvisação ou composição em tempo real, mas inclui na sua pauta que é nessa direção que se deve direcionar o olhar do criador de dança. Cada um desses momentos que fornece elementos para a composição. Noverre reconhece essa condição a que estamos sujeitos. Na Carta 6 , mais uma vez sublinha: "O instante é a alma dos quadros; é difícil de captá-lo e ainda mais difícil transmiti-lo com veracidade" (ibdem, p. 229)

Parecendo dialogar com filósofos e cientistas contemporâneos, como llya Prigogine que afirma: "temos não só leis, mas também eventos que não são dedutíveis das leis, mas atualizam as suas possibilidades" (1996, p. 13). Noverre também em suas Cartas sublinha a noção de eventos que se atualizam, do momento ao qual o artista da dança precisa estar atento. Afinal, transparece a questão de fundo: "como conceber a criatividade humana ou como pensar a ética num mundo determinista?" (ibdem, p. 14) E, assim, ciência se aproxima da arte, que se aproxima da política porque são vetores da mesma natureza, que operam nesse mundo físico que vivemos. Es- sas colocações que falam de ética, falam de democracia, falam de liberdade, porque falam de modos como a vida se manifesta. Vida essa que Noverre insiste que seja incluída na pauta da arte da sua dança de ação. E daí seu fascínio e perigo.

\section{É perigoso criar}

Nãos será à toa que Noverre será impedido de atuar inicialmente na Ópera de Paris, guardião das normas de um balé praticamente imutável e soberano. No circuito que escapa a essa forte normatividade para dança na época Noverre acaba por encontrar espaço e ressonâncias em muitos outros recantos da Europa, sendo na Inglaterra considerado o Shakespeare da dança, tendo suas irrequietas proposições reconhecidas e admiradas. Na Carta 15 essa indolência é novamente colocada:
Todos aqueles a quem a imitação sub- juga esquecer-se-ão da bela natureza para pensar unicamente no modelo que os toca e seduz... Questione-se os artistas, pergunte-se a eles porque não se dedicam a serem originais, dan- do à sua arte uma forma mais simples, uma expressão mais verdadeira, um ar mais natural? Responderão, justifi- cando sua Indolência e sua preguiça, que temem cair no ridículo, já que é perigoso inovar, criar (Monteiro,1998, p. 386).

Perigoso para quem cria. Perigoso para quem tem contato com o que é criado fora do padrão e norma vigente. Isso num período que antecede a Revolução Francesa no qual o absolutismo se traduz com perfeição no projeto de balé idealizado, universalizante, ordenado e controlado. A proposta estética que ele traz é a de abrir-se às ordens possíveis ao invés de fechar-se em estruturas artificialmente na- 
turalizadas. Alinhando-se com a noção de verossimilhança de Aristóteles, parece reafirmar que "quando plausível, o impossível se deve preferir a um possível que não convença" (Aristóteles, 1997, p. 48). A sua imitação da natureza, não é uma ordem redutora, mas amplificadora de possibilidades, pois essa natureza se estabelece no que se estabelece a cada nova ação. O seu balé de ação é feito dessas danças que emergem e se atualizam constante e insistentemente.

Inclusive há de enfatizar que o estilo epistolar, escolhido por Noverre revela outra coerência e peculiaridade com suas proposições. Ele não publica um manual, com orientações de passos e instruções do bem dançar e se comportar ${ }^{3}$, como era usual naquele período pelos mestres de balé (Tomazzoni, 2010). Como alertou Marianna Monteiro:

Muitas vezes, vê-se Noverre organizando os conceitos de forma puramente ornamental, preocupado, sobretudo com o funcionamento deles na elocução. Corre-se o risco de atribuir-lhe significados fixos, que nãos e sustentarão quando cotejados com outros trechos em que também são empregados (Monteiro, 1998, p. 29).

As Cartas partem de um desejo de diálogo, de confronto de ideias, pois por mais que a resposta não venha, é esboçada. Ao lançar ideias, esperam-se considerações e não ape-

3 Entre essas obras estão: O Tratado dos principaes fundamentos da dança, escrito por Natal Jacome Bonem, e publicado em Coimbra, em 1767: "obra muito útil, não somente para esta mocidade, que quer aprender a dançar bem, mais ainda para as pessoas honestas, e polidas, as quais ensina as regras para bem andar, saudar, e fazer todas as cortesias que convêm". Ou ainda: A coreografia ou a arte de descrever a dança por caracteres, figuras e sinais demonstrativos através dos quais se aprende facilmente por si mesmo todos os tipos de dança, (La Chorégraphier ou l'Arte de écrire la danse par caracteres, figures et signes démonstratifs avec lesquels on apprend facilment de soy-même toutes sortes de danses, 1700), de Raoul-Auger Feuillet. nas concordância. Como também percebeu Monteiro (1998)

[...] o que Noverre perde em estruturação ganha em porosidade, criando, através desses espaços intermediários, uma margem de liberdade para estabelecer, em caráter assistemático, o arcabouço conceitual de sua reforma da dança" (p. 29)

Não é como o gênero dos manuais, instrutivo, mas sim provocativo, combativo, numa escrita atravessada por engenho, emoção e criatividade para fortalecer o caráter argumentativo sobre aquilo que versa. Por isso me permito esse exercício de liberdade ao trafegar por seus conceitos e ideias, por vezes, até contraditórias. É esta tensão que carrega suas Cartas também de lacunas e brechas para serem interpretadas.

Lamentável não terem sobrevivido seus balés de ação ao longo do tempo. Ou quem sabe essa tenha sido a melhor herança que hoje impede que sejam tidos como modelos de reprodução ilustrativa. Fica o espaço aberto para imaginação, tão valiosa para ele. Quantas gradações teriam sua Medéia pra dançar o dilacerante conflito dessa mãe que mata os filhos. Que dança terá sido essa? Como seus preceitos do balé de ação, ele encontrou espaço ou limitações para concretizar seu projeto? Em que grau ou medida seus conceitos apareciam ou desapareciam na suas obras?

Não quero com isso descartar que seus ideais acabaram mais por operar consolidando um modelo balético que pouco fugiu das normas que criticou. Como observou Monteiro (1998): "Quanto à dança acadêmica, Noverre oscilaria entre uma atitude de compromisso e negação" (p. 15).

Talvez as condições culturais, sociais e polí- 
ticas do período em que Noverre criava, como também já destacou a pesquisadora Rosa Maria Hércoles (2005), o impediram a práxis desses preceitos de maneira plena e mesmo a sua devida difusão, o que em nada impede de se verificar a potencialidade desse material para discussões atuais das artes cênicas. Um material que busquei organizar em blocos distintos e sintéticos apenas para destacá-los e ressaltá-los, mas que se autoreferem e retroalimentam desrespeitando fronteiras por se interligarem e fazerem sentido na sua urdidura que atravessam todas as suas Cartas. Um material o qual me permiti fazer conexões com conceitos estéticos, científicos e filosóficos que não se traduzem por familiaridades ou lógicas teóricas uniformes ou concordantes entre si, mas que permitem articular de maneira até mesmo caótica ou indisciplinada com os preceitos das Cartas de Noverre. Mas acima de tudo um material valioso, fértil e atual para promover problematizações ainda necessárias. Um material gerado no fazer de bailarino, professor, criador, pesquisador de dança que Noverre foi, sem separar esses saberes/fazeres/poderes para pensar de maneira crítica e articulada a arte da dança e instaurar uma poética que se não conseguiu reformular o balé do seu tempo, introduziu perturbações que ainda ecoam e desafiam.

Referências

ARISTÓTELES. A poética clássica. São Paulo: Editora Cultrix, 1997.

BANES, Sally. Greenwich Village 1963. Rio de Janeiro: Rocco, 1999.
DAMÁSIO, Antonio. O Erro de Descartes. São Paulo: Editora Companhia das Letras, 1998. HÉRCOLES, Rosa Maria. Formas de comunicação do corpo - novas cartas sobre a dança. Tese de Doutorado em Comunicação e Semiótica. Programa de Pós Graduação em Comunicação e Semiótica, Pontifícia Universidade Católica, São Paulo, 2005.

LOUPPE, Laurence. Poética da Dança Contemporânea. Tradução de Rute Costa. Lisboa: Orfeu Negro, 2012.

NOVERRE, Cartas Sobre a Dança. Marianna Monteiro. São Paulo, Edusp/Fapesp, 1998.

PAREYSON, Luigi. Os problemas da estética. 3a ed. São Paulo: Martins Fontes, 1997.

Estética, teoria da formatividade. Petrópolis: Vozes, 1993.

PEREIRA, Roberto. Entre o céu e a terra. IN: Lições de Dança 2. Rio de Janeiro: Editora da UniverCidade, 2000.

PRIGOGINE, Ylia. O fim das certezas - tempo, caos e as leis da natureza. São Paulo: Editora de Universidade Estadual Paulista, 1996.

TOMAZZONI, Airton. Dançando e aprendendo a ser: estratégias de subjetivação nos manuais de dança. Idança Txt - volume 4 - Agosto/ 2011. Disponível em http://idanca.net/wp-content/uploads/2011/09/idancatxt_vol4_spread. pdf.

Recebido em: 02/06/2016 Aprovado em: 16/09/2016 